\title{
Factors Influencing the Adoption of Exclusive Breastfeeding Practices Among Teenage Rural Mothers in Ogun and Oyo State, Nigeria
}

\author{
Ogunwemimo, Funmilayo. Omolola ${ }^{1} \quad$ Adeoye, Adekunle. Stephen ${ }^{2 *}$ \\ James, Sarah. Adewunmi ${ }^{1} \quad$ Jimoh, Ganiyat O. ${ }^{1}$ \\ 1.Department of Home Economics. Federal College of Education, Abeokuta, Ogun State. Nigeria P.M.B. 2016. \\ Abeokuta. Ogun State, Nigeria \\ 2.Department of Agricultural Extension and Rural Development, Federal University of Agriculture, Abeokuta. \\ (FUNAAB) P.M.B 2240. Abeokuta. Ogun State, Nigeria
}

\begin{abstract}
The feeding of an infant with breast milk only for six months exclusion of all other feeds, liquids or solids, including water except approved by medical doctor for a reason; within the first half year of life is referred to as exclusive breastfeeding (EBF). in spite of its numerous benefits, not every mothers practiced it because of one reason or the other. This study examined the factors influencing the adoption of exclusive breastfeeding practices among teenage rural mothers in Ogun and Oyo State, Nigeria. Explorative research design and multi-stage sampling method was used to select respondents for the study and structured questionnaire was administered to four hundred and fifteen (415) teenage rural mothers, In-depth interviews were also held with breastfeeding rural mothers and ten (10) focus group discussion session with grandmothers in the study area. The result reveals that $59.1 \%$ and $61.0 \%$ of the respondents were between the age range of $17-19$ with the mean age of 19years and majority (81.4\% and 93.0) was Yoruba in Ogun and Oyo State respectively. Majority $(60.9 \%$ and $62.0 \%)$ of the respondents receive information about exclusive breastfeeding in the study location, while above half $(51.6 \%$ and 55.5\%) of the respondents in Oyo and Ogun State indicated that they practice exclusive breastfeeding in the study area. Most (36.3\% and 37.5\%) of the respondents in Oyo and Ogun States admitted that they breastfeed their child for more than 11 times on a daily basis in Ogun and Oyo State respectively. Result revealed that personal determination/experience $(\overline{\mathrm{x}}=3.73$ and 3.78), encouragement from their mothers $(\overline{\mathrm{x}}=3.72$ and 3.76) and nurse and midwife advice ( $\overline{\mathrm{x}}=3.70$ and 3.55) in Oyo and Ogun State respectively. Regression result shows that factors such as age, household size, educational level, ethnicity, occupation and place of delivery are seen to be significant and have positive relationship with factor influencing the adoption of exclusive breast feeding in the study area. It was concluded that compliance to Exclusive Breastfeeding for six months was still minima in Ogun and Oyo State. The study therefore recommended that policies aimed at improving exclusive breastfeeding uptake should also incorporate significant others (grandmothers, mothers in- laws, and husbands) in the process of encouraging breastfeeding mothers.
\end{abstract}

Keywords:Factors Influencing; Perception: Adoption: Rural; Exclusive Breastfeeding: Teenage Rural Mothers. DOI: $10.7176 / \mathrm{JEP} / 12-33-10$

Publication date: November $30^{\text {th }} 2021$

\section{Introduction}

Inappropriate feeding practices among infant during the first two years of life are a major cause of undernutrition in young children. The number of global deaths and disability-adjusted life-years caused by under nutrition constitutes the largest proportion of any risk factors in children under the age of five (Black et al. 2013). Children who are undernourished during the first two years of life and who then gain weight rapidly later in childhood, are in greater risk of chronic diseases in later life. The need to protect, promote and support breastfeeding in our communities has been widely recognized by many in both rural and urban area of our country Nigeria. Furthermore, the local context, such as culture, economy, agriculture and healthcare, affects practices and feeding decisions (Black et al., 2013, Stewart et al., 2013, Paul et al., 2011). According to some scholars such as Jones, Steketee, Black, Bhutta and Morris (2003), Ip, Chung, Raman, Trikalinos and Lau (2009), assert that a child who is Exclusively Breastfeed (EBF) for six months is more likely to be protected from gastrointestinal infections, respiratory illness, morbidity and death. EBF can also protect the child from atopic eczema (Ip, Chung, Raman, Trikalinos and Lau 2009), the risk of allergy, asthma, type II diabetes (Malla, Giri and Karki, 2011). Poor infant and young child feeding practices have been identified as a major contributor to the high burden of childhood morbidity and mortality in many countries. According to the Nigerian Demographic and Health Survey (NDHS), in 2008 17\% of children were exclusively breastfed for less than 4 months, while $13 \%$ were exclusively breastfed for less than 6 months. The median exclusive breastfeeding period in Southwest Nigeria by months in the year 2003 was 7 months. In the year 2008, it was 6 months. Within the same period, early initiation of breastfeeding among women in the region was $12.7 \%$ in 2003 , but increased 
to $35.5 \%$ in the year 2008 (NPC/ICF, 2009).

Breastfeeding practices, including initiation and duration, are influenced by multiple interwoven factors which include health, psychosocial, cultural, political, and economic factors (Cripe, 2008). Among these factors, decisions regarding initiation and duration of breastfeeding in low-income countries are influenced by education, employment, place of delivery, family pressure, and cultural values (WHO, 2005, Gartner 2005, Ogunlesi, 2010, Henry et al., 2010 and Otoo, Lartey and Perez-Escamilia, 2009). In Nigeria, while breastfeeding initiation is on the increase, the duration, and practice of exclusive breastfeeding among women who had their delivery in a health facility, and outside such facility, has remained low (Ogunlesi, 2010). The early introduction of complementary feeding, based on erroneous assumptions, affects breastfeeding initiation and sustainability (WHO, 2005). Among the Yoruba people, a common belief around infant feeding is that exclusive breastfeeding is beneficial to both infants and mothers, but complementary feeding is essential for babies to adapt to other meals with ease (Ojofeitimi et al., 2000, Lawoyin, et al., 2001 and Tella et al., 2008). Maternal characteristics such as age, income, education, knowledge, and ethnicity have been associated with the initiation and continuation of EBF (Wiener and Wiener, 2011). The lack of support, encouragement, and education from healthcare professionals, family, and friends can become barriers to exclusive breastfeeding (Moore and Coty, 2006; Murimi, Dodge, Pope, and Erickson, 2010). Even though many researchers have studied the prevalence of breastfeeding in the United States, only a few studies are available to provide trends in breastfeeding practices among mothers during the early weeks of postpartum (Bai et al., 2011; Brand, Kothari, and Stark, 2011; Scott, Landers, Hughes, and Binns, 2001). In Nairobi, Kenya, a prevalence of $13.3 \%$ was reported for exclusive breastfeeding (Lakati, Binno and Stevenson, 2002), which is lower than 33\% reported by Nyanga, Musda, Otieno and Kaseje (2012) in a study, among women in Nyando district, Kenya. In Nigeria, the prevalence of exclusive breastfeeding has varied widely from $67 \%$ in Jos, north-central (Ogbonna and Daboer, 2007), 52.9\% in Lagos, southwest (Okafor, Olatona and Olufemi, 2014) to 37.3\% in Anambra, southeast (Ukegbu, Ebenebe, Ukegbu and Onyeonoro, 2011) and a national average of $17 \%$, as reported in the Nigeria Demographic and Health Surveys of 2003 and 2013 (NPC,2004, 2014).

According to Agunbiyade and Ogunleye (2012) in their study of breastfeeding mothers in Southwest Nigeria found a prevalence of 16\%,citing baby's continued hunger after feeding, maternal health problem, fear that their infants could get addicted to breast milk, breast pains, and undue pressure from mothers-in-law to stop breastfeeding, as some of the barriers. Furthermore, Ugboaja, et al., (2013) and Ellattar et al., (2008) reported a higher but not impressive prevalence of $35.9 \%$ among urban women in southeast Nigeria. Further studies (Ugboaja, et al., (2013); Agbo et al., 2011; Agunbiyade and Ogunleye 2012) have linked the persistence of these harmful breastfeeding practices to the influence of the grandmothers. In addition, good maternal education, antenatal and postnatal care attendances have been significantly associated with increased EBF while increasing maternal age tends to have the opposite effect on the respondents (Sholeye, Abosede and Salako, 2015). However, not much is known about contemporary EBF practice and about the setbacks thereof, particularly among teenage mothers who residing in the rural suburbs of Southwest, Nigeria. The findings of this study may provide more information on the factor influencing the practice of Exclusive Breastfeeding in many rural suburbs of the Southwest Nigeria. It will hopefully contribute to fine-tune and enrich the breastfeeding initiative and policy of the country under the Ministry of Health. Furthermore, the findings will be useful as health education tools for rural and urban communities and the general public, and will serve as an important database for subsequent research in similar ways. The objectives of this study are to describe the socio-economic characteristics of the teenage mothers in the study area; determine the awareness and knowledge of exclusive breastfeeding among teenage mothers; perception of teenage rural mothers on exclusive breastfeeding and factor influencing the adoption of exclusive breastfeeding practices in the study area.

\section{Hypothesis of the study}

Ho1: There is no significant relationship between the socio-economic characteristics of the teenage mothers and the perception of teenage mothers about exclusive breastfeeding in the study area. (Chi-square and PPMC)

Ho2: There is no significant relationship between the socio-economic characteristics of the teenage mothers and the factors influencing the adoption of exclusive breastfeeding practices in the study area

\section{Methodology \\ Ethical consideration}

Ethical approval for the study was obtained from the research and ethics committee of the Federal College of Education, Abeokuta before commencement of the research work. Permission for the study was obtained from the council of Chiefs, rural community leaders and verbal consent was obtained from the study participants (i.e teenage rural mother). 


\section{Research Designand study area:}

Explorative study according to (Creswell, 2003) is useful in studying under researched topics, such as the subject matter of this paper. It is especially useful for discovery and gaining insight or understanding of emerging social issues (Babbie, 2007). All teenage rural mothers that presented with children under twenty-four months were sampled for the study. The study participants had free consultation and counseling about the benefit associated with the focus of the study. The researcher, assistant and enumerators administered and filled questionnaires which included the teenage rural mothers' age, occupation, and educational level, number of children, marital status etc; their awareness and knowledge of EBF; perception and factors influencing EBF practices in the study area. The entire southwest lies in the humid tropical zone bordered by a mangrove swamp forest in the South. Major parts of the study area lie in the fresh water swamp forest and rain forest to the South, which turns to moist and dry woodland savannah towards the North. It has a land area of about 114,271square kilometres (about $12 \%$ of total land mass of Nigeria, lying between latitude $4^{0}, 21^{1}$ and $9^{0}, 23^{1}$ North of the equator and longitude $2^{0}, 25^{1}$ and $6^{0}, 31^{1}$ East. The three main agro-ecological zones in the area are the swamp on the Atlantic coast, tropical rainforest in the middle and guinea savannah in the north. The area experience both the dry and wet seasons, the rainy season start from March and continue till October while the dry season commences in November and lasts till February. This study was carried out in Southwest Nigeria, which covers Lagos, Ekiti, Ogun, Ondo, Osun and Oyo State mainly dominated by the Yoruba ethnic group. The total population of the area is 27,581,992 with Lagos state having 9,013,534; Oyo 5,591.598; Ondo 3,441,024; Osun 3,423, 535; Ogun 3,728,098 and Ekiti having 2,384212; (National Population Census 2006). The study was viewed from the geopolitical zones. Agriculture forms the base of the overall development thrusts of the zone, with crop and livestock farming as the main occupation of the people in the study area.

\section{Population of the study:}

The population of the study comprises of teenage rural mothers in Ogun and Oyo State, Nigeria.

\section{Sampling procedure and sample size}

A multi-stage sampling method was used in the selection of teenage rural mothers in the study areas. The stages include: Out of the six (6) States, based on geo-political classifications, two (2) States were randomly selected which are Ogun and Oyo State. In each selected state, two agricultural zones were randomly selected. In each agricultural zone selected and with the assistance of the extension agent some agrarian communities were sampled for the study, from which three communities were randomly selected making a total of twelve communities for the study. This study employed the random sampling technique whereby respondent was sampled from different communities within the study area. The respondents were interviewed by approaching the teenage rural mothers that has a child within aged less than or equal to $1-6$ months. The sample size was determined using the single proportion formula. According to Armitage and Berry (1994), (the formula is suggested since the population size is less than 10,000). This formula gives precise estimates of population parameters and their differences. It gives more powerful statistical test. Ten (10) grandmothers that met the study inclusion criteria were recruited for the focus group discussion.

Sample size calculation. The formula is calculated thus:

$$
\mathrm{n}=\frac{(Z \alpha)^{2} \cdot \mathrm{p}(1-\mathrm{p})}{\mathrm{d}^{2}}
$$

Where $(Z \alpha)^{2}=(1.96)^{2}, p=0.5, d^{2}=0.05^{2}$

By substitution:

$$
\mathrm{n}=\frac{1.96^{2} \cdot 0.5(1-0.5)}{0.05^{2}} \quad=384
$$

$10 \%$ of calculated sample size was added to accommodate attrition. $n=(10 \%$ of 384$)+384=422$.

Of the 455 rural teenage mothers who responded to the researcher, only 415 responses from the intervieweradministered questionnaire were valid and used for the analysis. Hence, the analysis was based on 415 valid responses, representing a response rate of $91.2 \%$. In the qualitative strand, a purposive sampling approach was adopted in recruiting 10 nurses each in the two States in the pediatrics unit of the health facility. 15 grandmothers that met the study inclusion criteria were recruited for the focus group discussion.

\section{Research Instruments}

Three research instruments consisting of questionnaire, in-depth interview and focus group discussion were adopted to explore the rural teenage mother breastfeeding beliefs, practices and factors influencing EBF in the selected states for the study.

\section{Data analysis}

Data was entered onto an excel spreadsheet and presented in form of tables. Data was analyzed using SPSS 
version 21.0. Test of significance between proportions was assessed using Chi-square, Pearson Product Moment Correlation and Regression for the hypotheses of the study. A 95\% confidence interval was used and a p-value of less than 0.05 was considered significant.

\section{Result and Discussion}

Four hundred and fifteen rural teenage mothers from Ogun and Oyo State with their children age under less than 2 months to above 5 months of age were interviewed. As shown in Table 1, above half (59.1\%) of the respondents were between the $17-19$ years in Oyo State, while majority $(60.0 \%)$ of the respondents were between $17-19$ years in Ogun State, $29.3 \%$ and $27.0 \%$ of them were in the $20-22$ years of age and few $(11.6 \%$ and $12.0 \%$ ) of the respondents were less than 17 years of age. The mean age of the respondents was 18 years in both states. This result negates the result of work done by Somefun, et al., (2016) Ugboaja, et al. (2013) and Takai, et al. (2015). Half (51.6\% and 50.0\%) of the respondents in Ogun and Oyo State were married while $48.4 \%$ and $50.0 \%$ of them were separated. Majority $(67.4 \%$ and $72.5 \%)$ of the respondents were practicing Christianity, $27.9 \%$ and $22.5 \%$ of them practice Islam and few $(4.7 \%$ and $5.0 \%)$ of them practice traditional religion in Ogun and Oyo State. This implies that all the three religions were being observed by the respondents sampled. Most $(81.4 \%$ and $93.0 \%)$ of the respondents were Yoruba in the two State, while few $(8.4 \%$ and $3.0 \%$, $7.4 \%$ and $2.0 \%, 2.8 \%$ and $2.0 \%$ ) were Hausa, Igbo and Igede by ethnicity respectively. The mean household size was 3 and 4 persons in Ogun and Oyo State respectively. Majority $(73.0 \%$ and $71.5 \%)$ of the respondents in Ogun and Oyo State had formal education ranging from primary to tertiary education respectively, while $27.0 \%$ and $28.5 \%$ of them in Ogun and Oyo State had no formal education before being known as nursing mothers. The highest percentage $(27.9 \%$ and $25.5 \%)$ of the respondents in Ogun and Oyo State were practicing farmers, while $19.1 \%$ and $22.5 \%$ were traders, $23.7 \%$ and $22.0 \%$ were artisan respectively in the study area. Result revealed that highest percentage $(38.6 \%$ and $38.0 \%)$ of the respondents in Ogun and Oyo State had home delivery as their place of birth, while $29.3 \%$ and $31.0 \%$ had traditional birth attendant, $17.7 \%$ and $17.0 \%$ utilized private hospital and 14.4\%and 14.0\% utilized public hospital as their place of birth in Ogun and Oyo State respectively.

Table 1: Distribution based on socio-economic characteristics of the rural teenage mothers $(n=215$ and 200).

\begin{tabular}{|c|c|c|c|c|}
\hline \multirow[b]{2}{*}{ Variables } & \multicolumn{2}{|c|}{ Ogun state } & \multicolumn{2}{|c|}{ Oyo state } \\
\hline & Frequency & Percentage (\%) & Frequency & Percentages (\%) \\
\hline \multicolumn{5}{|l|}{ Age } \\
\hline Less than 17 & 25 & 11.6 & 24 & 12.0 \\
\hline $17-19$ & 127 & 59.1 & 122 & 61.0 \\
\hline $20-22$ & 63 & 29.3 & 54 & 27.0 \\
\hline Mean age & & 18.39 & & 18.25 \\
\hline \multicolumn{5}{|l|}{ Marital status } \\
\hline Married & 111 & 51.6 & 100 & 50.0 \\
\hline Separated & 104 & 48.4 & 100 & 50.0 \\
\hline \multicolumn{5}{|l|}{ Religion } \\
\hline Christianity & 145 & 67.4 & 145 & 72.5 \\
\hline Islam & 60 & 27.9 & 45 & 22.5 \\
\hline Traditional & 10 & 4.7 & 10 & 5.0 \\
\hline \multicolumn{5}{|l|}{ Ethnicity } \\
\hline Hausa & 18 & 8.4 & 6 & 3.0 \\
\hline Yoruba & 175 & 81.4 & 186 & 93.0 \\
\hline Igbo & 16 & 7.4 & 4 & 2.0 \\
\hline Igede & 6 & 2.8 & 4 & 2.0 \\
\hline \multicolumn{5}{|l|}{ Household size } \\
\hline Less than 4 & 59 & 27.4 & 54 & 27.0 \\
\hline $4-6$ & 91 & 42.3 & 105 & 52.5 \\
\hline $7-9$ & 65 & 30.2 & 41 & 20.5 \\
\hline \multicolumn{5}{|l|}{ Educational level } \\
\hline No formal education & 58 & 27.0 & 57 & 28.5 \\
\hline Primary education & 69 & 32.1 & 52 & 26.0 \\
\hline Secondary education & 46 & 21.4 & 47 & 23.5 \\
\hline Tertiary education & 42 & 19.5 & 44 & 22.0 \\
\hline \multicolumn{5}{|l|}{ Occupation } \\
\hline Farming & 60 & 27.9 & 51 & 25.5 \\
\hline Trading & 41 & 19.1 & 45 & 22.5 \\
\hline Civil servant & 38 & 17.7 & 37 & 18.5 \\
\hline
\end{tabular}




\begin{tabular}{lcccc}
\hline Artisan & 51 & 23.7 & 44 & 22.0 \\
Unemployed & 25 & 11.6 & 23 & 11.5 \\
Place of delivery & & & & \\
Public hospital & 31 & 14.4 & 28 & 14.0 \\
Private hospital & 38 & 17.7 & 34 & 17.0 \\
Traditional birth & 63 & 29.3 & 62 & 31.0 \\
Home delivery & 83 & 38.6 & 76 & 38.0 \\
\hline
\end{tabular}

Source: Field survey, (2018)

\section{Awareness and knowledge of exclusive breastfeeding among rural teenage mothers}

Result in Table 2 revealed that $33.0 \%$ and $32.0 \%$ of the respondents in Oyo and Ogun State start feeding their babies within the first 2 hours after delivery, $19.5 \%$ and $28.0 \%$ of them start feeding their babies after more than 2 hours of delivery and $20.9 \%$ and $13.5 \%$ of them start feeding their babies on the second day after birth due to one reason or the other, but $20.9 \%$ and $11.0 \%$ of them cannot remember when they started feeding their babies. Majority $(60.9 \%$ and $62.0 \%)$ of the respondents receive information about exclusive breastfeeding in the study location, while above half $(51.6 \%$ and $55.5 \%)$ of the respondents in Oyo and Ogun State indicated that they practice exclusive breastfeeding in the study area. Also, more than half (56.3\%) and majority $(61.0 \%)$ of the respondents indicated that they perceived adequacy of information about exclusive breastfeeding practices. It was gathered that majority $(62.2 \%)$ of the respondents in Oyo State and almost half $(46.9 \%)$ of the respondents in Ogun State practiced exclusive breastfeeding for over 8 weeks, while $14.4 \%$ and $23.4 \%$ of the respondents in Oyo and Ogun States practiced exclusive breastfeeding for just $5-6$ weeks in the study area. Most (36.3\% and $37.5 \%$ ) of the respondents in Oyo and Ogun States admitted that they breastfeed their child for more than 11 times on a daily basis in Ogun and Oyo State respectively, while 32.6\% and 32.0\% breastfeed their child for $9-$ 11 times a day, $18.1 \%$ and $15.5 \%$ breastfeed for $6-8$ times and $13.0 \%$ and $15.0 \%$ breastfeed for up to 6 times on a daily basis. It was observed that $26.5 \%$ and $33.0 \%$ of the respondents in Oyo and Ogun State opined that they intend to breastfeed their babies for 13 - 18 months, while $26.5 \%$ and $32.0 \%$ of them intend to breastfeed for $7-12$ months, $18.6 \%$ and $20.5 \%$ of them intend to breastfeed their babies for 6 months and $13.0 \%$ and $3.0 \%$ of them intend to breastfeed their babies for $19-24$ months. These findings are consistent with the findings of other studies that it is not only maternal intention and attitude, but many other maternal demographic and individual variables associated with predicted breastfeeding duration (Bai et al., 2011; Sheehan et al., 2010; Scott et al., 2001; Lawton et al., 2012). Finding reveals that $43.7 \%$ and $42.0 \%$ of the respondents in Oyo and Ogun State respectively reveals that they did not know the length of times or take count at all for each breastfeeding while $39.5 \%$ and $41.5 \%$ revealed half an hour for the length of times for each breastfeeding in the study area.

"Many of the breastfeeding rural mothers stated that they do not take notice of the duration of breastfeeding, most especially at night. Child breastfeeding at night was a common practice among the sampled respondents". (A teenage mother comment during an in-depth interview in Oyo State) "From my own experiences, after retiring from the labour work, farm or workplace breastfeeding at night while asleep is much easier than while am awake doing something or attending to some task and it is still a common practice among us to date and we learn it through our mother as a common norm (FGD with some teenage mothers in Ogun State)."

Result reveals that $50.7 \%$ and $43.5 \%$ of the respondents in in Oyo and Ogun State breastfeed the babies with breastfeed and formula for the first four weeks, while $45.1 \%$ and $52.5 \%$ of them breastfeed their babies with exclusive breastfeeding for the first four weeks and $4.2 \%$ and $4.0 \%$ of them breastfeed their babies with formula feed only. Majority (65.6\% and 61.5\%) of the respondents in Oyo and Ogun State revealed that exclusive breastfeed has maternal benefit in the study area. Others benefits of exclusive breastfeeding among the respondents sampled in Oyo and Ogun State were relief pain (43.7\% and 42.5\%), bonding (24.2\% and 36.5\%) and saving money $(32.1 \%$ and $21.0 \%)$ among the teenage rural mothers sampled. This implies that majority of the teenage rural mother has fair knowledge about exclusive breastfeeding practices in the two States sampled for this study; this is in line with the submission of Alade et al., (2013) in their study of exclusive breastfeed as they recorded fair knowledge of practices of exclusive breastfeeding among lactating mothers in a rural community in Southwest Nigeria. Results of the present study show that some of the teenage rural mothers with good knowledge of the benefits of exclusive breastfeeding were more likely to breast feed exclusively if adequate attention and proper diet if given to them, which will encourage others to follow suit. This is similar to reports from other studies in Nigeria (Ukegbu, et al., 2011) Sri-Lanka (Agampodi, 2008) and Ireland (Zhou, et al., 2010). This result is not surprising as it has been demonstrated that high maternal knowledge about exclusive breastfeeding and infant health benefits from this practice was directly related to maternal intention. Also, several scholars (Maduforo, et al., 2013) which show high maternal knowledge of exclusive breast feeding also report high exclusive breastfeeding rates whereas those (Chaudhary, et al., 2011) with low maternal knowledge 
also report low exclusive breastfeeding practice rate.

Table 2: Awareness and Knowledge of exclusive breastfeeding

\begin{tabular}{|c|c|c|c|c|}
\hline \multirow{2}{*}{ Variables } & \multicolumn{2}{|c|}{ Oyo } & \multicolumn{2}{|r|}{ Ogun } \\
\hline & Frequency & $\begin{array}{l}\text { Percentages } \\
(\%)\end{array}$ & Frequency & $\begin{array}{l}\text { Percentages } \\
(\%)\end{array}$ \\
\hline \multicolumn{5}{|l|}{ When did you start to feed your baby } \\
\hline Immediate after birth & 12 & 5.6 & 31 & 15.5 \\
\hline Within the first $2 \mathrm{hrs}$ & 71 & 33.0 & 64 & 32.0 \\
\hline After more than $2 \mathrm{hrs}$ & 42 & 19.5 & 56 & 28.0 \\
\hline On the second day after birth & 45 & 20.9 & 27 & 13.5 \\
\hline Cannot remember & 45 & 20.9 & 22 & 11.0 \\
\hline $\begin{array}{l}\text { Receive information about exclusive } \\
\text { breastfeeding }\end{array}$ & & & & \\
\hline Yes & 131 & 60.9 & 124 & 62.0 \\
\hline No & 84 & 39.1 & 76 & 38.0 \\
\hline \multicolumn{5}{|l|}{ Did you practice exclusive breastfeeding } \\
\hline Yes & 111 & 51.6 & 111 & 55.5 \\
\hline No & 104 & 48.4 & 89 & 44.5 \\
\hline \multicolumn{5}{|l|}{ Perceived adequacy of information } \\
\hline Yes & 121 & 56.3 & 122 & 61.0 \\
\hline No & 94 & 43.7 & 78 & 39.0 \\
\hline $\begin{array}{l}\text { For how long did you practice exclusive } \\
\text { breastfeeding? }\end{array}$ & $(n=111)$ & & $(n=124)$ & \\
\hline $1-2$ weeks & 3 & 2.7 & 2 & 1.8 \\
\hline $3-4$ weeks & 10 & 9.0 & 13 & 11.7 \\
\hline $5-6$ weeks & 16 & 14.4 & 26 & 23.4 \\
\hline $7-8$ weeks & 13 & 11.7 & 18 & 16.2 \\
\hline Above 8 weeks & 69 & 62.2 & 52 & 46.9 \\
\hline \multicolumn{5}{|l|}{ How often do you breastfeed your baby daily } \\
\hline Less than 6 times & 28 & 13.0 & 30 & 15.0 \\
\hline $6-8$ times & 39 & 18.1 & 31 & 15.5 \\
\hline $9-11$ times & 70 & 32.6 & 64 & 32.0 \\
\hline Above 11times & 78 & 36.3 & 75 & 37.5 \\
\hline \multicolumn{5}{|l|}{ Length of times for each breastfeeding } \\
\hline Less than half hour & 36 & 16.7 & 33 & 16.5 \\
\hline Half an hour & 85 & 39.5 & 83 & 41.5 \\
\hline I don't know & 94 & 43.7 & 84 & 42.0 \\
\hline \multicolumn{5}{|l|}{$\begin{array}{l}\text { What periods are you intend to breastfeed } \\
\text { your baby }\end{array}$} \\
\hline Less than 6month & 33 & 15.3 & 23 & 11.5 \\
\hline 6 months & 40 & 18.6 & 41 & 20.5 \\
\hline $7-12$ months & 57 & 26.5 & 64 & 32.0 \\
\hline $13-18$ months & 57 & 26.5 & 66 & 33.0 \\
\hline $19-24$ months & 28 & 13.0 & 6 & 3.0 \\
\hline \multicolumn{5}{|l|}{$\begin{array}{l}\text { During first four weeks of delivery what type } \\
\text { of breastfeeding practices did you use }\end{array}$} \\
\hline Exclusive breastfeeding & 97 & 45.1 & 105 & 52.5 \\
\hline Breastfeed and formula & 109 & 50.7 & 87 & 43.5 \\
\hline Formula feed only & 9 & 4.2 & 8 & 4.0 \\
\hline \multicolumn{5}{|l|}{ Exclusive breastfeeding has maternal benefit } \\
\hline Yes & 141 & 65.6 & 123 & 61.5 \\
\hline No & 74 & 34.4 & 77 & 38.5 \\
\hline \multicolumn{5}{|l|}{ Other benefits of exclusive breastfeeding } \\
\hline Saving money & 69 & 32.1 & 42 & 21.0 \\
\hline Relief pain & 94 & 43.7 & 85 & 42.5 \\
\hline Bonding & 52 & 24.2 & 73 & 36.5 \\
\hline
\end{tabular}

Source: Field survey, 2018 


\section{Perception of exclusive breastfeeding among teenage rural mothers in the study area.}

The mean scores of teenage rural mothers' perception about exclusive breastfeeding in Oyo and Ogun State are presented in Table 3. The results show that all the twenty (20) perception statements in Oyo state has the mean values greater than 3.00 while perceptions of teenage rural mothers about exclusive breastfeeding in Ogun State showed that seventeen (17) statement has the mean value greater than 3.00 and three (3) perception statement has mean value less than 3.00. Perceptions of respondents about exclusive breastfeeding which is the cut-off point to determine respondents' feelings about exclusive breastfeeding practices. Result reveals that the mean perception of exclusive breastfeeding in Oyo State indicated that exclusive breastfeeding is for rich people in the society were with the mean value of $(\overline{\mathrm{x}}=4.16 \pm 1.029)$ and am still young to rely only on exclusive breastfeeding were with the mean value of $(\overline{\mathrm{x}}=4.12 \pm 0.952)$, there is tendency for me to lose weight were with the mean value of $(\overline{\mathrm{x}}=3.96 \pm 1.02)$, work/business issue affect me once I return were with the mean value of $(\overline{\mathrm{x}}=3.89 \pm 1.25), \mathrm{I}$ am not eating balance diet were with the mean value of $(\overline{\mathrm{x}}=3.87 \pm 1.99)$ based on the perception of teenage rural mothers about exclusive breastfeeding in Oyo State. In Ogun State, result showed that exclusive breastfeeding is for rich people in the society were with the mean value of $(\bar{x}=4.11 \pm 1.06)$ and am still young to rely only on exclusive breastfeeding wee with the mean value of $(\overline{\mathrm{x}}=3.96 \pm 0.95)$, there is tendency for me to lose weight were with the mean value of $(\bar{x}=3.94 \pm 0.88)$, fear of loss of my breast shape were with the mean value of $(\bar{x}=$ $3.78 \pm 1.08)$, Work/business issue affected me once I return were with the mean value of $(\overline{\mathrm{x}}=3.76 \pm 1.25)$ based on the perception of teenage rural mothers about exclusive breastfeeding in Ogun State. While other perception statement was more severely felt by the teenage rural mothers with higher mean values. The average mean rating of exclusive breastfeeding perception indicated that exclusive breastfeeding had more to do on teenage rural mothers in Oyo State $(\overline{\mathrm{x}}=3.70 \pm 1.14)$ than Ogun State $(\overline{\mathrm{x}}=3.55 \pm 1.15)$ teenage rural mothers. All these imply that there seems to be no difference in the perception of exclusive breastfeeding among teenage rural mothers as perceived in Oyo and Ogun State. Early breastfeeding for an infant, helps in improving the child's psychological and physical health, as well as improving the child's immune system (National Resources Défense Council, 2001). The benefits of breastfeeding are numerous to mentions if well adhere to by nursing mothers. The human milk glycans contain oligosaccharide, which helps in the formation of natural immunological mechanism. This helps to protect children against infectious diseases (Lamberti et al, 2011). However, in order for an infant to get maximum benefits of breast milk, the mother must have an adequate balance diet. Malnutrition among teenage rural mothers increases their level of risks that a mother would face during pregnancy, delivery and breastfeeding of child. In 2001, the effects of exclusive breastfeeding for 6 months vs. 3-4 months were studied in order to find out the difference between EBF for 6 months and months less than 6 . The research resulted in endorsement for supporting and encouragement of exclusive breastfeeding up to six months of age. This is because the study found out that children that are exclusively breastfed turned out to be healthier and more energetic (Lamberti et $a l ., 2011)$. This submission is in line with the findings from the in-depth interview.

"What kind of difference do one expect on the outcome of child being fed with exclusive breastfeeding for 6 months over other without or less exclusive breastfeeding, there will be great changes from such child. I have seen one which entice me to embark on the practice now and ready to inform others to embarked on exclusive breastfeeding in my area" In-depth interview, Iwo (2017).

"What affected us was lack of malnutrition, encouragement and poor information about exclusive breastfeeding. If women ate good food at the right time and drink good herb as is it during their own time nobody will see any difference. But on the long run she encourages the use of exclusive breastfeeding for all rural women and say it is the present act and urge them to do it well for 6 months."

Table 3: Perception of teenage rural mothers about exclusive breastfeeding practices in the study area.

\begin{tabular}{lcccc}
\hline & \multicolumn{2}{c}{ Oyo $(\mathbf{n}=\mathbf{2 1 5})$} & \multicolumn{2}{c}{ Ogun $(\mathbf{n}=\mathbf{2 0 0})$} \\
\hline Perception & Mean & Std. dev & Mean & Std. dev \\
\hline The baby never satisfies and continue to be hungry & 3.73 & 1.08 & 3.71 & 1.25 \\
There are maternal health challenges for the mothers & 3.77 & 1.05 & 2.53 & 1.11 \\
There is fear of infant becoming addicted to breast milk alone & 3.23 & 1.29 & 2.96 & 1.35 \\
Occurrence of pain in the breast & 3.63 & 1.23 & 3.62 & 1.14 \\
I was not making enough breast milk to satisfy my child & 3.45 & 1.19 & 3.39 & 1.35 \\
Work/business issue affected me once I return & 3.89 & 1.25 & 3.76 & 1.25 \\
Lack of support from my husband & 3.72 & 1.19 & 3.61 & 1.14 \\
I feel tiring and restless after breastfeeding the baby & 3.17 & 1.28 & 2.93 & 1.36 \\
Lot of pressure to wean the baby from neighbours & 3.48 & 1.41 & 3.23 & 1.47 \\
Baby refuse to be breast feeding & 3.60 & 1.19 & 3.58 & 1.12 \\
There is tendency to lose weight & 3.96 & 1.02 & 3.94 & 0.88 \\
I feel dizzy at times during breastfeeding of my baby & 3.73 & 1.12 & 3.52 & 1.25 \\
\hline
\end{tabular}


Delay in another pregnancy

Fear of loss of my breast shape

My baby is not gaining enough weight

I was not eating balance diet

Exclusive breastfeeding is for rich people in the society

I cannot rely alone on breast milk for my child

Am still young to rely only on exclusive breastfeeding

Exclusive breastfeeding will not allow baby to eat well later

Average rating of perception of exclusive breastfeeding

Source: Field survey, (2018)

Factors that can influence the adoption of exclusive breastfeeding practices in the study area.

With the level of breastfeeding awareness among the respondents sampled in Oyo and Ogun State, it was important to understand the factors that could help the teenage rural mothers in deciding to be involved in exclusive breastfeeding practices. The result in Table 6 showed that personal determination/experience was with the mean value of 3.73 and 3.78 in Oyo and Ogun State respectively. This implies that the majority of the respondents had a strong will and learns from people about the issue of breastfeeding with the understanding of the nutritional benefit attributed to breast milk. However, it was gathered that encouragement from their mothers was with the mean value of 3.72 and 3.76 in Oyo and Ogun State respectively. This is an indication that most grandmothers support adequate breastfeeding for a certain period. In the FGD, four of the grandmothers recounted how their involvement in breastfeeding had helped their daughter-in-law to initiate and continue breastfeeding, although not exclusively, but continued breastfeeding up to a year and beyond, while three of the grandmothers also support satisfactory breastfeeding practices which have help people over time, exclusive breastfeeding was practiced by my daughter-in-law to initiate and continue to practice. Furthermore, nurse and midwife advice were with the mean value of 3.70 and 3.55 in Oyo and Ogun State respectively. The health personnel instruction during ante-natal and postnatal help respondents to adopt the use of exclusive breastfeeding practices to some extent in the study area. A more probe on factor influencing the adoption of exclusive breastfeeding showed that social pressure on mothers was with a mean value of 3.67 and 3.64 , and encouragement from mother-in-law was with the mean value of 3.67 and 3.64 in Oyo and Ogun State respectively attracted similar value and proportions. Also, Encouragements from husbands were with the mean value of 3.59 and 3.64, and neighbours support and advice were with the mean value of 3.59 and 3.64 in Oyo and Ogun State Nigeria respectively attracted equal value. In the in-depth interviews with nurses, some of them described their involvement in regular health education and quality information on breastfeeding practices during antenatal and postnatal visits to the health facility.

Table 6: Factor influencing the adoption of exclusive breastfeeding practices.

\begin{tabular}{lcccc}
\hline & \multicolumn{2}{c}{ Oyo $(\mathbf{n}=\mathbf{2 1 5})$} & \multicolumn{2}{c}{ Ogun $(\mathbf{n}=\mathbf{2 0 0})$} \\
\hline Factor influencing & Mean & Std. dev & Mean & Std. dev \\
Encouragement from mothers & 3.72 & 1.148 & 3.76 & 1.179 \\
Social pressure on mothers & 3.67 & 1.139 & 3.64 & 1.200 \\
Personal determination/experience & 3.73 & 1.148 & 3.78 & 1.179 \\
Husband encouragement at all time & 3.59 & 1.304 & 3.64 & 1.253 \\
Nurse and midwife advice & 3.70 & 1.033 & 3.55 & 1.050 \\
Encouragement from mother-in-law & 3.67 & 1.139 & 3.64 & 1.200 \\
Media and publicity & 3.68 & 1.033 & 3.55 & 1.050 \\
Neighbours support and advice & 3.59 & 1.304 & 3.64 & 1.253 \\
Religious bodies role and encouragement & 2.95 & 1.149 & 3.70 & 1.148 \\
Availability of a balanced diet & 2.78 & 1.116 & 3.42 & 1.241 \\
\hline Source:
\end{tabular}

Source: (Field survey, 2018)

Hypotheses of the study

Ho1: There is no significant relationship between the demographic characteristics of the teenage rural mothers and their perception of about exclusive breastfeeding in the study area.

The result of the Chi-square analysis in Table 5 shows that there is significant relationship $(\mathrm{p}<0.05)$ between marital status $\left(\chi^{2}=8.499, \mathrm{df}=4, \mathrm{p}<0.319\right)$, level of education $\left(\chi^{2}=47.020, \mathrm{df}=4, \mathrm{p}>0.011\right)$ place of delivery $\left(\chi^{2}=26.465, \mathrm{df}=3, \mathrm{p}<0.021\right)$, occupation $\left(\chi^{2}=58.145, \mathrm{df}=4, \mathrm{p}<0.001\right)$, religion $\left(\chi^{2}=44.125, \mathrm{df}=2, \mathrm{p}<0.001\right)$ ethnicity $\left(\chi^{2}=24.805, \mathrm{df}=3, \mathrm{p}<0.033\right)$ and the perception of about exclusive breastfeeding in the study area. The result of the analysis revealed that all these variables measured have significant relationship with the perception of about exclusive breastfeeding in the study area. This study found that practice of EBF was significantly influenced by maternal education, occupation, place of delivery, skilled attendant at birth, husband's education, and occupation. However, marital status did not have a significant association with practice 
of EBF. These are similar to the findings of previous studies (Agbo et al., 2011; Sadoh et al., 2011 Agunbiade et al., 2012). A similar study in Nigeria reported place of delivery maternal education, maternal occupation, skilled attendance, socio economic status and EBF in the study area. (Egenti, et al., 2018).

Table 4: Chi-square analysis between the demographic characteristics of the respondents' and perception of about exclusive breastfeeding in the study area

\begin{tabular}{lllll}
\hline Variables & $\boldsymbol{\chi}^{\mathbf{2}}=$ value & Df & p-value & Decision \\
\hline Marital status & 8.499 & 2 & 0.319 & $\mathrm{NS}$ \\
Level of Educational & 47.020 & 4 & 0.011 & $\mathrm{~S}$ \\
Occupation & 58.145 & 4 & 0.001 & $\mathrm{~S}$ \\
Place of delivery & 26.465 & 3 & 0.021 & $\mathrm{~S}$ \\
Ethnicity & 24.805 & 3 & 0.033 & $\mathrm{~S}$ \\
Religion & 44.125 & 2 & 0.001 & $\mathrm{~S}$ \\
\hline
\end{tabular}

\section{Source: Field survey, 2018}

Note: $\quad \mathrm{S}=$ Significant at 0.05 level, $\quad \mathrm{NS}=$ Not significant at 0.05 level.

The result of correlation in Table 6 shows that there is significant relationship $(p<0.05)$ between the age $(r=-$ $0.158)$, household size $(\mathrm{r}=0.130)$ of the respondents and the perception of about exclusive breastfeeding in the study area. This implies that age, and household size has a determinant factor to the perception of about exclusive breastfeeding in the study area. The negative sign in age implies an inverse proportion to the perception of about exclusive breastfeeding in the study area.

Table 5: Correlation result between the demographic characteristics of the respondents' and perception of about exclusive breastfeeding in the study area.

\begin{tabular}{llll}
\hline Variables & r-value & p-value & Decision \\
\hline Age & -0.158 & 0.013 & $\mathrm{~S}$ \\
Household size & 0.130 & 0.001 & $\mathrm{~S}$ \\
\hline
\end{tabular}

Source: Field survey, 2018

Note: $\quad \mathrm{S}=$ Significant at 0.05 level,

$\mathrm{NS}=$ Not significant at 0.05 level.

Ho2: There is no significant relationship between the socio-economic characteristics of the teenage mothers and the factors influencing the adoption of exclusive breastfeeding practices in the study area (Regression).

The result of the regression analysis is presented in Table 9. Dependent variable in the model as seen in Table 9 as factors influencing the adoption of EBF and the independent variables are age, sex, marital status, religion, household size, educational level, ethnicity, occupation and place of delivery. Table 9 shows the result of the multiple regression models. Considering the regression model, it gives a coefficient of multiple determinations $\left(\mathrm{R}^{2}\right)$ of 0.47 . This implies that variations in the explanatory variables explained only $47 \%$ of total variation of factor influencing the adoption of EBF (dependent variable). The result shows that the overall regression equation was significant at 0.05 probability level, since prob $>\mathrm{F}=0.001$. Factors such as age, household size, educational level, ethnicity, occupation and place of delivery are seen to be important to factor influencing the adoption of exclusive breast feeding in the study area. They are significant and have a positive relationship with factor influencing the adoption of exclusive breastfeeding. For instance, place of delivery of the respondents is an important because where the teenage rural mothers received information will have demonstrated that teenage rural mothers with good information and knowledge of exclusive breastfeeding will be more likely to breastfeed their infants exclusively in the first six months. The factors associated with breastfeeding practice in this study are similar to findings from other studies. Maternal educational status was associated with breast feeding practice which is similar to findings from Jos, North central Nigeria (Ogbonna and Daboer, 2007), Nyando district, Kenya (Nyanga, Musda, Otieno, and Kaseje, 2012) and in the developed world (Kronborg and Vaeth, 2004). This however contrasts with findings from Sokoto, North western Nigeria, where level of education had no association with the practice of exclusive breastfeeding (Umar and Oche, 2013). As reported by researchers in Sokoto, occupation was not associated with breastfeeding practice in this study (Umar and Oche, 2013). This however contrasts with several studies in which occupation (particularly paid employment), has been shown to be associated with breastfeeding practices and also documented to be a barrier to the practice of exclusive breastfeeding (Nyanga, Musda, Otieno, and Kaseje, 2012, Agbo, Envuladu, Adams, Inalegwu, Okeh, Agba et al., 2013; Ministry of Health 2011; Stewart-Glenn, 2008). In contrast with studies from Jos (Ogbonna and Daboer, 2007), Sokoto (Umar and Oche, 2013) and Kenya (Nyanga, Musda, Otieno, and Kaseje, 2012, Ministry of Health 2011) maternal age was not associated with the practice of exclusive breastfeeding. Although about a quarter $(25.4 \%)$ of respondents had experienced pain while breastfeeding, it was not associated with the practice of exclusive breastfeeding; a contrast with a previous study, which found breastfeeding practice to be associated with the mothers' previous breastfeeding experience and self-efficacy with respect to breastfeeding (Kronborg and Vaeth, 2004). 
Table 14: Analysis of the relationships between socio-economic characteristics and the factors influencing the adoption of EBF

\begin{tabular}{llllll}
\hline & Coefficients & Std. Error & $\mathrm{T}$ & $\mathrm{p}$-value & Decision \\
\hline (Constant) & 4.623 & 0.30 & 15.60 & 0.000 & \\
Age & -0.052 & 0.12 & -0.16 & 0.018 & $\mathrm{~S}$ \\
Sex & -0.064 & 0.13 & -0.07 & 0.95 & $\mathrm{NS}$ \\
Marital status & 0.264 & 0.12 & 0.17 & 0.087 & $\mathrm{NS}$ \\
Religion & -0.473 & 0.13 & -0.18 & 0.086 & $\mathrm{NS}$ \\
Household size & -0.103 & 0.13 & -0.43 & 0.001 & $\mathrm{~S}$ \\
Educational level & -0.122 & 0.09 & 0.70 & 0.004 & $\mathrm{~S}$ \\
Ethnicity & -0.101 & 0.11 & 1.34 & 0.001 & $\mathrm{NS}$ \\
Occupation & 0.042 & 0.11 & 0.35 & 0.003 & $\mathrm{~S}$ \\
Place of delivery & 0.162 & 0.06 & 0.05 & 0.005 & $\mathrm{~S}$ \\
Distance to farm & 0.546 & 0.31 & 0.35 & 0.004 & $\mathrm{~S}$ \\
$\mathrm{R}^{2}$ & 0.47 & & & & \\
Adjusted R & 0.38 & & & & \\
F-Ratio $^{2}$ & 8.32 & & & &
\end{tabular}

Source: field survey, 2018.

$* * *, * *, *$ show significance levels at 1,5 and $10 \%$, respectively

\section{Conclusion and Recommendation}

Conclusion

Based on the findings of this study, compliance to Exclusive Breastfeeding by teenage rural mothers in Ogun and Oyo State was still at minimal level of utilization in Ogun and Oyo State, Nigeria under the study. The occupation of the teenage rural mothers was found to have a big influence, with mothers on informal and no employment being more compliant to Exclusive Breastfeeding in some part of the study area. Teenage rural mothers are faced with multiple problems as they strive to practice exclusive breastfeeding to some extent in the selected area. Thus, scaling up of exclusive breastfeeding among teenage rural mothers requires concentrated efforts at the macro, meso, and micro levels of Nigerian society. Retrogressive the existing brain drain in the Nigeria health sector will require substantial improvements in working conditions, and empowering of healthcare providers to provide improved care and dissemination of vital information when necessary to many teenage rural and urban mothers in the Country. Present infant feeding practices were found to be associated with the following demographic variables: age, marital status of mother, level of education, and employment status of mother. Findings from this study show some of the possible problems that might undermine the achievement of the Millennuim Development Goal 4 of preventing child mortality in Nigeria and to the WHO and UNICEF's policy of exclusive feeding for the first six months. This finding is worrying and problematic in view of the health and immunological benefits of exclusive breastfeeding. The vast majority of teenage rural mothers in the two selected state practice mixed feeding despite their proximity to the institution and access to healthcare providers.

\section{Recommendation}

The study recommends the following:

1. There is an urgent need of policies that will aim at providing acceptable food supplements that could aid the supply of breast milk among postpartum mothers, especially those with low socio-economic status.

2. Policies aimed at improving exclusive breastfeeding uptake should also incorporate significant others (grandmothers, mothers in- laws, and husbands) in the process of encouraging breastfeeding mothers.

3. Health workers and authorities do not only target the mother as the sole recipient of infant feeding education, but also other caregivers including relatives, friends, the general community, and public at large, since anyone could be a reference point or a significant other for a lactating mother.

4. Also, infant feeding educators should take into consideration the culture and meanings of practices of the mothers they educate since cultural beliefs are very difficult to change.

\section{Acknowledgment}

The research team genuinely registers our deep appreciation to Tertiary Education Trust Fund (TETFUND) Abuja. The Provost Federal College of Education Osiele, Abeokuta, Ogun State Nigeria, Dr. A.A Ajayi, the 
management team, and the TETFUND Desk Officer, Mr. A. A. Abati for granting us the endorsement and release of funds to carry out this research work titled "Assessment of Exclusive Breastfeeding Practices among Teenage Rural Mothers in Selected Agrarian Community of Southwest Nigeria". The authors also wish to acknowledge Primary Health Care (PHC) in the most agrarian community in Oyo and Ogun State for permitting us to meet the teenage rural mothers within their premises. Finally, we thank our respondents (teenage rural mothers), Nurses, and Grandmothers in both Oyo and Ogun states for their co-operation and support. We also wish to thank our anonymous reviewers for their very useful contribution, correction, and comments which helped to bring the paper to the present level.

This researcher work was proudly sponsored by:

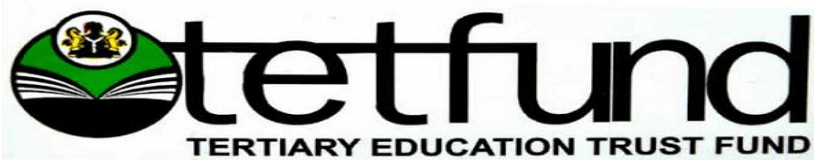

\section{References}

Agampodi, S. B, Agampodi T. C. (2008). Effect of low-cost public health staff training on exclusive breastfeeding. Indian J Pediatr. 75: 1115-1119. 10.1007/s12098-008-0185-4.

Agbo, H. A, Envuladu, E. A, Adams, H. S, Inalegwu, E, Okeh, I, Agba, A. et al. (2013). Barriers and facilitators to the practice of exclusive breastfeeding among working class mothers: a study of female resident doctors in tertiary health institutions in Plateau State. E3 Journal of Medical Research. 2(1):112-116.

Agho, Kingsley E., et al. (2011). "Determinants of exclusive breastfeeding in Nigeria." BMC Pregnancy and Childbirth, Vol. 11, No. 1, p. 2.

Agunbiade, O. M, and Ogunleye, V. O. (2012). Constraints to exclusive breastfeeding practice among breastfeeding mothers in southwest Nigeria: implications for scaling up. Int Breastfeed J. 2; 7: 5.

Alade, O. Titiloye, M. A. Oshiname, F. O.and Arulogun, O. S. (2013). "Exclusive breastfeeding and related antecedent factors among lactating mothers in a rural community in Southwest Nigeria," International Journal of Nursing and Midwifery, vol. 5, no. 7, pp. 132-138.

Babbie, E. (2007). The practice of social research. London: Thomson Wadsworth.

Bai, Y.K., Wunderlich, S., and Fly, A. (2011). Predicting intentions to continue exclusive breastfeeding for 6 months: A comparison among racial/ethnic groups. Maternal \& Child Health Journal, 15(8), 1257-1264. doi:10.1007/s10995-010.

Black, R.E, Victora, C.G, Walker, S.P, Bhutta, Z.A, Christian, P, de Onis M et al. (2013). Maternal and child undernutrition and overweight in low-income and middle-income countries. Lancet; 382:427-51.

Brand, E., Kothari, C., \& Stark, M. (2011). Factors related to breastfeeding discontinuation between hospital discharge and 2 weeks postpartum. Journal of Perinatal Education, 20(1), 36-44. doi:10.1891/10581243.20.1.36

Chaudhary, R. N, Shah, T, and Raja, S. (2011). Knowledge and practice of mothers regarding breast feeding: a hospital-based study. Health Renaissance. 9:194-200.

Creswell, J. (2003). Research design: Qualitative, quantitative and mixed methods approaches (2nd ed.). Thousand Oaks, CA: SAGE Publications.

Cripe, E. T. (2008). Supporting breastfeeding(?):nursing mothers' resistance to and accommodation of medical and social discourses. In Emerging Perspective in Health Communication: Meaning, Culture and Power. Edited by: Zoller HM, Dutta MJ. New York: Routledge Taylor and Francis Group; 2008:63-84.

Egenti, N. B, Adamu, D. B, Chineke, H. N. and Adogu, P. O. U. (2018). Exclusive Breastfeeding among Women in Rural Suburbs of Federal Capital Territory, Abuja, Nigeria. International Journal of Medical Research \& Health Sciences, 2018, 7(1): 57-64.

Elattar, A., et al. (2008). "Factors influencing maternal length of stay after giving birth in a UK hospital and the impact of those factors on bed occupancy." Journal of Obstetrics and Gynaecology, Vol. 28, No. 1, pp. 7376.

Gartner, L.M, Morton, J, Lawrence, R.A, Naylor, A.J, O’Hare, D, Schanler, R.J, and Eidelman, A.I: (2005). American Academy of Pediatrics Section on Breastfeeding: Breastfeeding and the use of human milk. Pediatrics 2005, 115:496-506. 15.

Henry, B.A, Nicolau, A.I, Americo, C.F, Ximenes, L.O, Bernheim, R.G, and Oria, M.O.B: (2010). Sociocultural factors influencing breastfeeding practices among low- income women in Fortaleza-Ceara-Brazil: a Leininger's sunrise model perspective. Enfermeria Global [http://www.um.es/eglobal].

Ip, S, Chung, M, and Raman, G. (2009). "Breast feeding and maternal and infant health outcomes in developed countries". Evidence Report/Technology Assessment; 153: 1-186.

Jones G, Steketle, R. W, Black, R. E, Bhutta, Z. A, and Morris, S. S, (2003). Bellagio child survival strategy 
group. How many child deaths can we prevent this year? Lancet. 362: 65 -71.

Kronborg, H, and Vaeth, M. (2004). The influence of psychosocial factors on the duration of breastfeeding. Scand. J. Public Health. 2004; 32(3): 210 - 216.

Lakati A, Binno C, and Stevenson M. (2002). The effect of work status on exclusive breastfeeding in Nairobi.Asia Pac J Public Health. 2002; 14(2): 85-90.

Lamberti, L. M., Walker, C. L. F., Noiman, A., Victora, C., and Black, R. E. (2011). Breastfeeding and the risk for diarrhea morbidity and mortality. BMC Public Health, 11(Suppl 3), 1-12. https://doi.org/10.1186/14712458-11-S3-S15.

Lawoyin, T. O., Olawuyi, J. F. and Onadeko, M. O. (2001). Factors associated with exclusive breastfeeding in Ibadan, Nigeria. J Hum Lact, 17(4):321-325.

Lawton, R., Ashley, L., Dawson, S., Waiblinger, D., and Conner, M. (2012). Employing anextended Theory of Planned Behaviour to predict breastfeeding intention, initiation, and maintenance in White British and South-Asian mothers living in Bradford. British Journal of Health Psychology, 17(4), 854-871. doi:10.1111/j.2044-8287.2012.02083.x.

Maduforo, A., Ubah N. C., and Okeke, P. (2013). The practice of exclusive breastfeeding by lactating women in Owerri metropolis, Imo State, Nigeria. Global Advanced Research Journal of Medical Sciences, 12(1): 013019.

Malla, D. S., Giri, K. and Karki, C. (2011).Chaudhary P. Achieving millennium development goals 4 and 5 in Nepal.BJOG. 118:60-68.

Ministry of Health- Kenya. (2011). Rapid qualitative assessment: beliefs and attitudes around infant and young child feeding in Kenya. Nairobi, Kenya. USAID / PATH / IYCN / UNICEF. 2011.

Moore, E. R., \& Coty, M. (2006). Prenatal and postpartum focus groups with primiparas: Breastfeeding attitudes, support, barriers, self-efficacy, and intention. Journal of Pediatric Health Care: Official Publication of National Association of Pediatric Nurse Associates \& Practitioners, 20(1), 35-46.

Murimi, M., Dodge, C. M., Pope, J., \& Erickson, D. (2010). Factors that influence breastfeeding decisions among special supplemental nutrition program for women, infants, and children participants from Central Louisiana. Journal of the American Dietetic Association, 110(4), 624-627. doi:10.1016/j.jada.2009.12.019

National Population Commission (Nigeria) (2014). Nigeria Demographic and Health Survey 2013. Rockville, Maryland, USA. National Population Commission and ICF International.

National Population Commission (NPC) and ICF Macro: (2009). Nigeria Demographic and Health Survey 2008 Calverton, Maryland, USA: NPC and ICF Macro; 2009.

National Resources Defense Council (NRDC). (2001). Healthy Milk, Healthy Baby: Chemical Pollution and Mother's Milk. Retrieved November 10, 2017, from https://www.nrdc.org/media/2001/010522.

Nyanga, N. M, Musda, C, Otieno, A, and Kaseje, D. (2012). Factors influencing knowledge and practice of exclusive breastfeeding in Nyando district, Kenya. African Journal of Food, Agriculture, Nutrition and Development. 12(6).

Ogbonna, C. and Daboer, J. C. (2007).Current knowledge and practice of exclusive breastfeeding among mothers in Jos, Nigeria. Niger J Med. 16(3):256-260.

Ogunlesi, T. A: (2010). Maternal socio-demographic factors influencing the initiation and exclusivity of breastfeeding in a Nigerian semi-urban setting. Matern Child Health J 14(3):459-465.

Ojofeitimi E. O, Esimai O. A, Owolabi, O. O, Oluwabusi, O. O. F, and Olanuga T. O. (2000) Breastfeeding practices in urban and rural health centers: impact of baby friendly hospital initiative in Ile Ife, Nigeria. Nutr Health, 14:119-125.

Otoo G. E, Lartey A. A, and Pérez-Escamilla R. (2009). Perceived incentives and barriers to exclusive breastfeeding among Periurban Ghanaian women. J Hum Lact 2009, 25(1):34-41.

Paul, K.H, Muti, M, Khalfan, S.S, Humphrey, J.H, Caffarella, R, and Stoltzfus, R.J. (2011). Beyond food insecurity: how context can improve complementary feeding interventions. Food Nutr Bull. 32:244-53.

Sadoh AE, Sadoh WE, Oniyelu P (2011). Breast feeding practice among medical women in Nigeria. Niger Med $J ; 52(1): 7-12$

Scott, J., Landers, M., Hughes, R., and Binns, C. (2001). Factors associated with breastfeeding at discharge and duration of breastfeeding. Journal of Pediatrics and Child Health, 37(3), 254-261.

Sheehan, A., Schmied, V., \& Barclay, L. (2010). Complex decisions: Theorizing women's infant feeding decisions in the first 6 weeks after birth. Journal of Advanced Nursing, 66(2), 371-380. doi:10.1111/j.13652648.2009.05194.x.

Sholeye, O. O., Olayinka A. A, and Albert A. S. (2015). "Exclusive breastfeeding and its associated factors among mothers in Sagamu, Southwest Nigeria." Journal of Health Science, Vol. 5, No. 2, pp. 25-31.

Somefun, O. D, and Latifat, I. (2016). "Determinants of postnatal care non-utilization among women in Nigeria." BMC Research Notes, Vol. 9, No. 1, 2016, p. 21.

Stewart, C.P, Iannotti, L, Dewey, K.G, Michaelsen, K.F, and Onyango, A.W. (2013). Contextualising 
complementary feeding in a broader framework for stunting prevention. Matern Child Nutr 2013;9(2):S27S45.

Stewart-Glenn J. (2008). Knowledge, perceptions and attitudes of managers, coworkers and employed breastfeeding mothers. AAOHN J. 2008; 56(10):423-429.

Takai, I. U. et al. (2015). "Factors responsible for under-utilization of postnatal care services in Maiduguri, north-eastern Nigeria." Sahel Medical Journal, Vol. 18, No. 3, 2015, p. 109.

Tella A, Falaye A, Aremu O, and Tella A: A. (2008). Hospital-based assessment of breast-feeding behavior and practices among nursing mothers in Nigeria and Ghana. Pak J Nutr, 7(1):165-171.

Ugboaja, J. O., et al. (2013). "Barriers to postnatal care and exclusive breastfeeding among urbanwomen in southeastern Nigeria.” Nigerian Medical Journal: Journal of the Nigeria Medical Association, Vol. 54, No. 1, p. 45.

Ukegbu, A. U, Ukaegbu, P. O, Onyeonoro, U. U, and Ubajaka, C. F. (2011). Determinants of breastfeeding among mothers in Anambra State, Nigeria. South Afr J Child Health. 5(4): $112-116$.

Umar, A. S, and Oche, M. O. (2013). Breastfeeding and weaning practices in an urban slum in Northern Nigeria. International Journal of Tropical Disease \& Health. 3(2): 114 - 125.

Wiener, R. C., \& Wiener, M. A. (2011). Breastfeeding prevalence and distribution in the USA and Appalachia by rural and urban setting. Rural \& Remote Health, 11(2), 1-9.

World Health Organisation (2005), WHO Progress Report, 2005-2006.

Zhou, Q, Younger, K.M, and Kearney J. M. (2010). An exploration of the knowledge and attitudes towards breastfeeding among a sample of Chinese mothers in Ireland. BMC Public Health 2010; 10: 722. 